\title{
Biocompatible Peritoneal Dialysis: The Target Is Still Way Off
}

\author{
Maria Bartosova and Claus Peter Schmitt* \\ Center for Pediatric and Adolescent Medicine Heidelberg, University of Heidelberg, Heidelberg, Germany
}

Peritoneal dialysis (PD) is a cost-effective, home-based therapy for patients with end-stage renal disease achieving similar outcome as compared to hemodialysis. Still, a minority of patients only receive PD. To a significant extend, this discrepancy is explained by major limitations regarding PD efficiency and sustainability. Due to highly unphysiological composition of PD fluids, the peritoneal membrane undergoes rapid morphological and long-term functional alterations, which limit the treatment and contribute to adverse patient outcome. This review is focused on the peritoneal membrane ultrastructure and its transformation in patients with kidney disease and chronic PD, underlying molecular mechanisms, and potential systemic sequelae. Current knowledge on the impact of conventional and secondgeneration PD fluids is described; novel strategies and innovative PD fluid types are discussed.

\section{OPEN ACCESS}

Edited by: Janusz Witowski,

Poznan University of Medical Sciences, Poland

Reviewed by:

Ramon Paniagua, Instituto Mexicano del Seguro Social (IMSS), Mexico

Miguel Perez Fontan, University of A Coruña, Spain

${ }^{*}$ Correspondence:

Claus Peter Schmitt clauspeter.schmitt@med. uni-heidelberg.de

Specialty section:

This article was submitted to Integrative Physiology,

a section of the journal

Frontiers in Physiology

Received: 21 September 2018 Accepted: 07 December 2018 Published: 07 January 2019

Citation:

Bartosova M and Schmitt CP (2019) Biocompatible Peritoneal Dialysis:

The Target Is Still Way Off.

Front. Physiol. 9:1853.

doi: 10.3389/fphys.2018.01853
Keywords: peritoneum, peritoneal dialysis, glucose, glucose degradation products, biocompatibility, transformation, transport, junctions

\section{PERITONEAL MEMBRANE ANATOMY AND PHYSIOLOGY}

The peritoneum is a delicate structure covering the entire peritoneal cavity. The parietal peritoneum is composed of a single layer of mesothelial cells and a submesothelial zone, which contains blood vessels, lymphatic vessels, and nerves that are mainly organized in a three layer structure (Blackburn and Stanton, 2014; Schaefer et al., 2016a) (Figure 1). The parietal peritoneal capillary density is age-dependent, with a two times higher blood vessel density in infants than in older children. In adults, peritoneal blood vessel density slowly increases with age but remains below the density observed in infants (Schaefer et al., 2016a). The age-dependent changes in peritoneal vascularization during childhood may be explained by the rapid increase in body dimension in early life, which should reduce a constant number of capillaries in an increasing tissue volume, as it is the case for the number of glomeruli found in a given cone kidney biopsy in children of different ages (Feneberg et al., 1998). Similar findings were observed for the lymphatic density, which overall is much lower than blood vessel density. Submesothelial thickness steadily increases until the age of 18 years and is again lower in adults. Respective percentile curves for age-appropriate evaluation of the peritoneum have been established (Schaefer et al., 2016a). The extracellular peritoneal matrix contains bundles of collagens and mucopolysaccharides and a small number of cells such as fibroblasts and mononuclear cells, including sparse CD45 lymphocytes and CD68 macrophages (Schaefer et al., 2016a).

The visceral peritoneum covers the abdominal organs and their supply structures, the mesentery, but no detailed systematic analyses across age groups have been performed. The omental peritoneum consists of a calretinine and podoplanin positive mesothelial cell layer as the parietal peritoneum. It covers the adjacent adipose tissue, which contains isolated bundles of large vessels and a much lower numbers of capillaries than the parietal submesothelium. The omental and parietal peritoneal blood capillary microvessel density are correlated. Thus, omental tissue specimen should be informative regarding the 


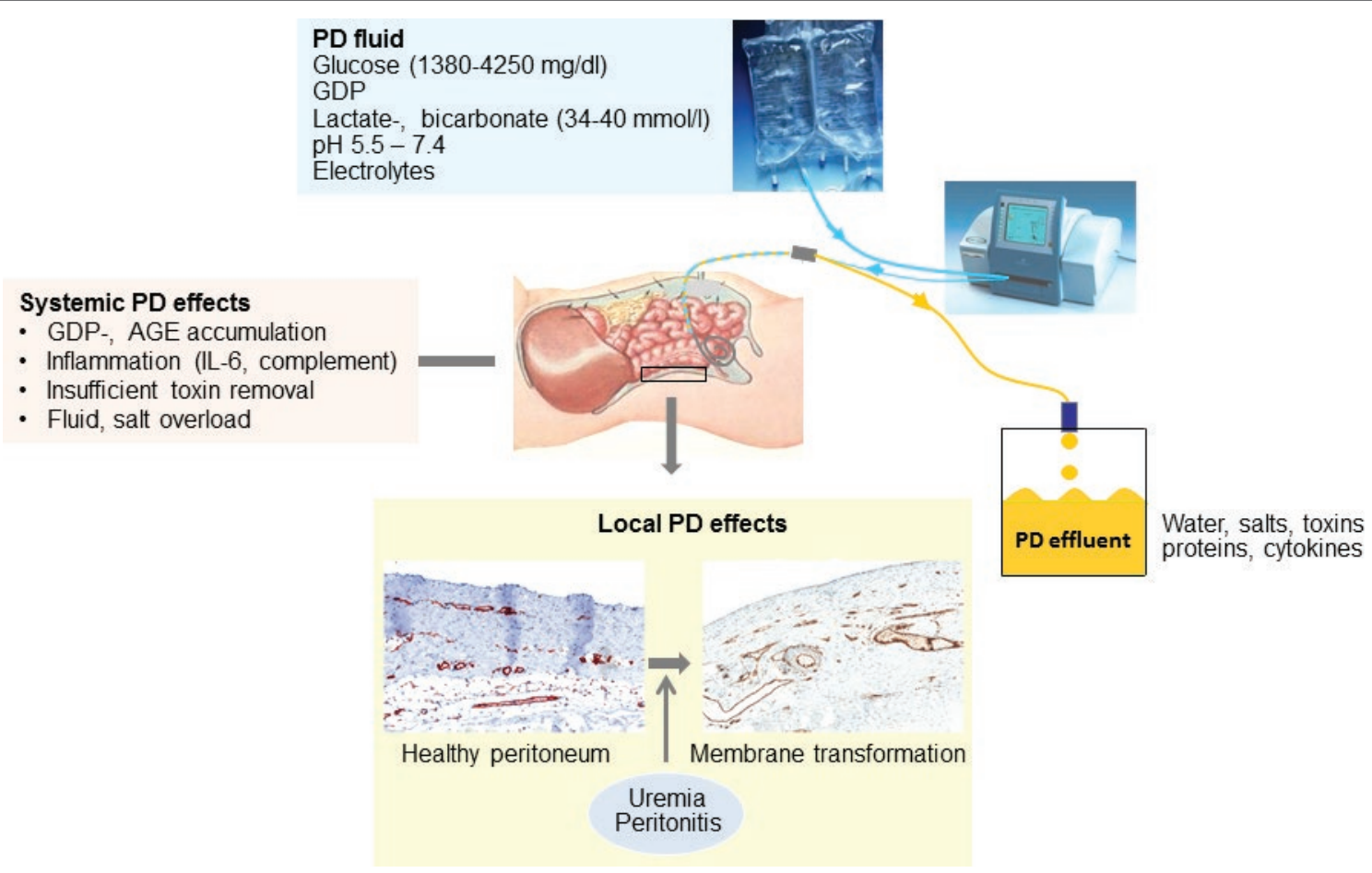

FIGURE 1 | Scheme of peritoneal dialysis application, peritoneal dialysis (PD) fluid composition, and local as well as systemic effects. Three vessel layer structure of the healthy peritoneal membrane as published previously (Schaefer et al., 2016a).

parietal peritoneal vessel density, at least in the non-diseased state (Schaefer et al., 2016a).

The peritoneum exerts numerous functions, many of which have already been recognized in the 19th century (Robinson, 1897; van Baal et al., 2017). The peritoneum maintains local homeostasis and provides protection from movement-induced frictions and adhesions by secretion of phospholipids, mainly phosphatidylcholine, together with surfactant proteins (SP-A, -B, -C) (Hills et al., 1998). In steady state, mesothelial cells produce $5-100 \mathrm{ml}$ of peritoneal fluid containing complement factors (Tang et al., 2004; Zelek et al., 2016), immunoglobulins (Davies et al., 1990), defensins (Grupp et al., 2007), and immune cells like macrophages, lymphocytes, eosinophils, and mast cells (van Baal et al., 2017) that exert antiinfectious actions and regulate the inflammatory response (IsazaRestrepo et al., 2018). In vitro, mesothelial cells migrate in an AQP-1-dependent manner (Ryu et al., 2012; Zhai et al., 2012), suggesting efficient wound healing capacity of superficial peritoneal erosions. Tissue remodeling is balanced by profibrotic cytokines and tissue inhibitors of metalloproteinase and by extracellular matrix degrading proteins such as metalloproteinases, gelatinase, and collagenase (Marshall et al., 1993; Ma et al., 1999). Plasminogen activator is responsible for a physiological fibrinolytic activity of peritoneum, and reduced concentrations following abdominal surgery promote adhesion formation (Holmdahl et al., 1996).

Angiogenesis in postnatal development is controlled by cytokines, including vascular endothelial growth factor (VEGF) and angiopoietins, and their receptors (Eklund and Saharinen, 2013). Angiogenesis is tightly regulated through a balance between activating and inhibiting signals (Fagiani and Christofori, 2013).
Adult vasculature is quiescent, but blood vessels retain a high plasticity in order to respond to angiogenic signals after inflammation or injury. These angiogenic mechanisms should also be active in the peritoneum.

The omental fat tissue (Summers, 2006) generates numerous hormones and cytokines involved in immune responses and angiogenic and neurogenic factors (Chamorro et al., 1993; Goldsmith, 2001). It is a lipid store and pools immune cells, and it can adhere to neighboring peritoneum to embank local inflammation (Hall et al., 1998).

Altogether, the peritoneum is of clinical impact in various conditions such as postoperative adhesions (Hills et al., 1998; Arung et al., 2011), in patients with abdominal and gynecological carcinoma (Lemoine et al., 2016), and in patients with chronic kidney disease stage $5 \mathrm{D}$ requiring dialysis (CKD5D). This review focuses on the usage of the semipermeable peritoneum as a biological dialysis membrane, its transformation with peritoneal dialysis (PD), and current concepts and future prospects to improve PD efficacy and sustainability.

\section{PERITONEAL DIALYSIS}

$\mathrm{PD}$ is a life-saving, renal replacement therapy for a worldwide increasing number of patients with CKD5D. PD removes excess water and electrolytes as well as metabolic waste products by osmosis across a concentration gradient between the blood and the PD fluid and ultrafiltration-associated solvent drag (convection). PD is a costeffective, home-based therapy and has significant advantages over 
hemodialysis (HD), in particular, regarding quality of life. Early patient outcome is at least similar to patients on HD (McDonald et al., 2009; Waldum-Grevbo et al., 2015). Despite these benefits, only a small number of dialysis patients receive PD, in Europe about $13 \%$ and in the USA about 10\% (Mehrotra et al., 2016; Kramer et al., 2018). This discrepancy is in part explained by major limitations of PD. Infectious complications, mainly peritonitis, and the PD fluid induced progressive deterioration of the PD membrane with chronic $\mathrm{PD}$, lead to PD function deterioration and eventually technique failure. As with hemodialysis, the uremic toxin and water removal capacity is far below physiological renal function. Most of the patients require strict dietary control and pharmacological treatment, such as phosphate binders, but the vast majority of patients are salt, fluid, and toxin overloaded. In particular, dietary phosphate and sodium intake are inadequately compensated by $\mathrm{PD}$ and essentially contribute to high blood pressure (Ortega and Materson, 2011), CKD mineral bone disorder, and cardiovascular disease (CVD). Mortality rates of both hemodialysis and PD patients are 40-fold higher compared to the age-related healthy population; accelerated cardiovascular disease is the primary cause of death (de Jager et al., 2009).

\section{PD FLUID COMPOSITION}

The osmotic agent most frequently applied is glucose. PD fluids contain glucose at concentrations of 10- to 50-fold above physiological serum concentrations. Glucose creates an osmotic gradient with an osmolality of about $50-150 \mathrm{mOsmol} / \mathrm{l}$ above serum osmolality allowing for removal of water (called "ultrafiltration") and of electrolytes and toxins by ultrafiltrationassociated convection. Correction of metabolic acidosis is achieved by uptake of a buffer compound, lactate or bicarbonate, present in the dialysate at concentrations of $34-40 \mathrm{mmol} / \mathrm{l}$.

First-generation PD fluids contain 35-40 mM lactate buffer and have an acidic $\mathrm{pH}$ of 5.5. The low $\mathrm{pH}$ aggravates the detrimental effects of the high lactate concentrations on peritoneal mesothelial and leukocyte function (Topley et al., 1988, 1996). During heat-sterilization and prolonged storage, high amounts of glucose degradation products (GDP) are formed, e.g., methylglyoxal and 3,4-dideoxyglucosone3 -ene. Peritoneal GDP exposure correlates with peritoneal advanced glycation end products (AGE) deposition and increasing peritoneal transporter status function, with the latter reflecting the PD fluidinduced peritoneal transformation process (Nataatmadja et al., 2018). GDP are rapidly absorbed into the circulation and increase systemic AGE concentrations (Zeier et al., 2003; Schmitt et al., 2007). AGE bind to the AGE receptor RAGE and trigger various intracellular events, such as oxidative stress and inflammation, leading to cardiovascular complications (Stinghen et al., 2016). Skin tissue AGE concentrations are increased in $\mathrm{PD}$ as compared to HD patients and independently associated with CV morbidity (Jiang et al., 2012).

To prevent GDP formation and to achieve a neutral to physiological $\mathrm{pH}$, second-generation PD fluids have been introduced 20 years ago. These separate the buffer compound, lactate and/or bicarbonate, from the glucose, which is kept at a very low $\mathrm{pH}$ to reduce GDP formation during heat sterilization and storage. Prior to administration, the compartments are mixed; the final $\mathrm{pH}$ of the ready-to-use fluid is 7-7.4. Depending on the manufacturing process, GDP formation is substantially reduced but still varies considerably between different brands (Erixon et al., 2006). Second-generation PD fluids significantly reduce systemic GDP load and circulating AGE concentrations. The impact of 10-20\% reduction in serum AGE concentrations achieved with low versus high GDP PD fluids on PD patient outcome, however, is still uncertain (Zeier et al., 2003; Schmitt et al., 2007).

PD fluids with an alternative osmotic agent contain icodextrin, a much less resorbed osmotic agent derived from starch. It allows for a slow but persistent colloid osmotic ultrafiltration and therefore can be used for a single long dwell per day (Dousdampanis et al., 2018; Morelle et al., 2018). Icodextrin fluid is especially applied in patients with high peritoneal solute transporter status and improves patient's hydration status (Cho et al., 2013). Despite the absence of glucose and the very low GDP content, the acidic PD fluid has been associated with increased local and systemic inflammation (Parikova et al., 2003; Martikainen et al., 2005; Moriishi and Kawanishi, 2008; Velloso et al., 2014). Another alternative to glucose-based PD fluids is amino acid containing solutions, which are free of GDP and have an only slightly acidic $\mathrm{pH}$ of 6.7. For optimized nutrition of malnourished patients and to prevent increased serum nitrogen levels and metabolic acidosis (Dombros et al., 1990), they should be applied at a ratio of 1-4 with glucose-containing PD fluids (Tjiong et al., 2005). The nutritional effects are limited; stable isotope studies in adult CAPD patients yielded a $4 \%$ higher protein synthesis rate than patients treated with glucose-containing PD solution only (Tjiong et al., 2007). The biocompatibility of amino acid fluids remains uncertain, and experimental studies and findings in humans do not unanimously support the notion of improved peritoneal biocompatibility. Rats exposed to amino acid PD fluid had less peritoneal AGE deposition, lower VEGF levels, and a lower vessel density compared to rats treated with first-generation PD fluid (Mortier et al., 2004). In vitro, mesothelial cells exposed to amino acid PD fluid synthesized less HSP72, released more IL-6 and prostaglandin E2, and had superior viability as compared to acidic, high GDP fluid (Bender et al., 2008). Others, however, reported more mesothelial nitric oxide (NO) synthesis (Reimann et al., 2004). NO plays a key signaling role in numerous biologic processes, including control of vascular tone and permeability, and angiogenesis, via an interaction with VEGF (Papapetropoulos et al., 1997). Human peritoneal endothelial $\mathrm{NO}$ synthase expression and activity increase with time on PD and are related to endothelial VEGF upregulation and peritoneal vessel density (Combet et al., 2000).

Altogether, limited progress has been achieved during the past 50 years of PD treatment regarding $\mathrm{PD}$ fluid technology and mainly consists of reduction of the GDP content, $\mathrm{pH}$ neutralization, introduction of the bicarbonate buffer and of two alternative osmotic compounds. Glucose-based PD fluids still predominate, and $\mathrm{PD}$ treatment still confers major local peritoneal and systemic toxicity (Figure 1) (Schmitt and Aufricht, 2016).

\section{PERITONEAL MEMBRANE TRANSFORMATION WITH CHRONIC PD}

In patients with $\mathrm{CKD} 5$, at the time of catheter insertion, the peritoneum already exhibits minor but distinct alterations, including submesothelial thickening and vasculopathy, as compared to controls 
with normal renal function (Williams et al., 2002). In diabetic patients, peritoneal changes at start of PD are even more pronounced and comprise mesothelial loss, mesothelial basement membrane thickening, vascular wall thickening, and inflammatory cell infiltration (Contreras-Velazquez et al., 2008). The latter and hypoalbuminemia are associated with technique failure and mortality rate. In pediatric $\mathrm{CKD} 5$ patients, an increase in parietal vessel density (Schaefer et al., 2018) was observed. In contrast, omental fat vessel density was found to be reduced in pediatric CKD5D, pointing to another distinct and early feature of CKD-related vascular disease (Burkhardt et al., 2016). Parietal peritoneal micromorphological changes are accompanied byvascular endothelial telomere shortening, mild inflammatory cell invasion, epithelial-to-mesenchymal transition (EMT), fibrin deposition, and TGF- $\beta$-induced SMAD phosphorylation (Schaefer et al., 2018). Compared to the subsequent PD-induced changes, morphological alterations are still mild and do not progress much in patients on HD (Williams et al., 2002).

In a landmark paper of Williams et al., severe transformation of the peritoneum was demonstrated with chronic $\mathrm{PD}$ in patients treated with acidic, high GDP fluids (Williams et al., 2002). These changes included progressive loss of the mesothelial cell layer, a massive increase in submesothelial thickness especially in patients with more than 4 years of $\mathrm{PD}$, and rapidly progressing, severe peritoneal vasculopathy. Number of peritoneal vessels per peritoneal section length was increased at the time of PD-related surgery and in patients with PD membrane failure, i.e., insufficient peritoneal transport function, as compared to a small group of patients with normal renal function. The study group did not relate their histologic findings to PD function and patient outcome; however, resulting therapeutic complications of long-term PD have repeatedly been described. Peritoneal solute transport gradually increases with time on $\mathrm{PD}$, particularly when increasing concentrations of glucose are applied (Davies et al., 1998, 2001). Ultrafiltration capacity declines and eventually results in long-term ultrafiltration failure, which is often characterized by impaired osmotic conductance to glucose and reduced free water transport (Krediet and Struijk, 2013). High solute transport predicts technique failure and is associated with poorer patient survival (Davies et al., 1998). Peritoneal protein clearance also increases during the course of $\mathrm{PD}$, but to a relatively smaller extend (Struijk et al., 1991; Ho-dac-Pannekeet et al., 1997).

Introduction of neutral $\mathrm{pH}$, low GDP fluids raised hope to prevent long-term deterioration of the peritoneal membrane, based on numerous in vitro and experimental in vivo studies. These studies suggested improved local host defense (Mortier et al., 2003), reduced mesothelial damage (Grossin et al., 2006) and EMT (Bajo et al., 2011), less peritoneal GDP and AGE deposition, less TGF- $\beta$ and VEGF signaling, and less submesothelial fibrosis and angiogenesis, altogether resulting in better preservation of peritoneal ultrafiltration capacity (Mortier et al., 2004, 2005; Rippe, 2009). Respective clinical trials were less consistent. Compared to first-generation PD fluids, administration of neutral $\mathrm{pH}$, low GDP fluids resulted in higher CA125 effluent concentrations (Haas et al., 2003; Szeto et al., 2007), a putative marker of mesothelial cell viability and lower hyaluronic acid and procollagen peptide concentrations, suggesting improved peritoneal membrane integrity (Williams et al., 2004). A declining incidence of encapsulating peritoneal sclerosis has been associated with low GDP fluid usage (Nakao et al., 2017). Residual renal function, a major predictor of patient outcome, was better preserved (Kim et al., 2008; Haag-Weber et al., 2010; Johnson et al., 2012b). While superior residual renal function during the first year of PD may be related to less-effective fluid removal and consequent volume expansion with neutral $\mathrm{pH}$, low GDP fluid, the long-term effect could be related to lower renal GDP and AGE exposure (Cho et al., 2014; Yohanna et al., 2015). The Euro-Balance trial, a randomized, two times 12-week crossover trial, demonstrated improved residual renal function together with decreased peritoneal ultrafiltration with the pH neutral, low GDP fluid, as compared to the firstgeneration, acidic high GDP solution (Williams et al., 2004). The largest study up to now, the BalANZ trial yielded a lower risk of anuria and lower ultrafiltration and higher solute clearance rates with the low GDP fluid during the first 9 months of PD. Over the entire 2 study years, the increase in solute transport and ultrafiltration decline were less pronounced with the low GDP fluid, resulting in comparable peritoneal membrane function at the study end with either fluid (Johnson et al., 2012b). A recent meta-analysis confirmed that neutral $\mathrm{pH}$, low-GDP solutions result in a higher $\mathrm{D} / \mathrm{P}$ creatinine during the first 6 months of treatment as compared to acidic, high GDP fluids but not subsequently (Yohanna et al., 2015). Peritonitis incidence and severity were reduced in the BalANZ trial and in another randomized, parallel trial over 2 years (Johnson et al., 2012a; Farhat et al., 2017), whereas other randomized trials did not report such differences (Williams et al., 2004; Szeto et al., 2007). Of note, these studies all compared the neutral $\mathrm{pH}$, lactate-buffered, low GDP fluid with the acidic, lactate-buffered, high GDP PD fluid. Consecutive 1-day and 12-week randomized crossover studies in children comparing physiological $\mathrm{pH}$, pure bicarbonate-buffered, low GDP fluid with first-generation PD fluid demonstrated similar ultrafiltration rates and a similar to $10 \%$ lower small solute transport rate with the former, which is in contrast to the reduced ultrafiltration and increased solute transport rates reported with neutral $\mathrm{pH}$, lactate-based, low GDP fluids (Schmitt et al., 2002; Haas et al., 2003).

Peritoneal biopsies are usually not performed within clinical routine and limited to occasion of abdominal surgery required for other reasons. On the other hand, they are well tolerated, even in small children, and highly informative. They provide information not only on acute inflammatory but also on chronic PD-induced peritoneal damage and should allow for a prognostic estimate of PD performance. Scientific impact of peritoneal tissue analysis is considerable. Based on findings in 100 patients with diseases not affecting the peritoneal integrity and 90 CKD5 patients at time of first PD catheter insertion, Schaefer et al. (2018) analyzed 82 children on PD with low GDP fluids and revealed unexpected findings. In patients with a median PD vintage of 4 months, peritoneal blood capillary density and number per section length doubled, endothelial exchange area increased, and the three-layer structure has turned to a rather homogenous vessel distribution. Hypervascularization further increased in the majority of patients after 9 months of PD and remained largely unchanged thereafter. Peritoneal vessel density independently predicted glucose and creatinine transport. Vasculopathy, already present at time of PD initiation significantly progressed. In contrast, lymphatic vessel density remained largely unchanged in all PD patient groups. Submesothelial thickening progressed slowly and was severe in patients on PD for more than 4 years. These changes were 


\section{Blood vessel density}

\section{Lymphatic vessel density}

\section{Vasculopathy}

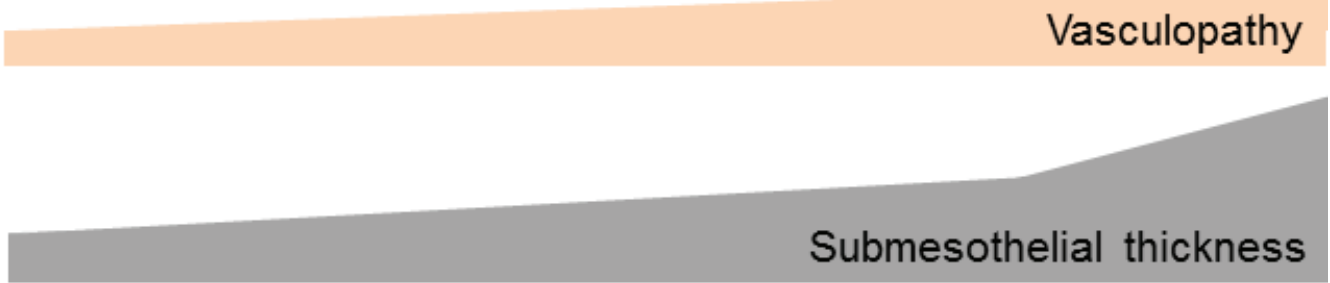

Years on PD (CKD5)

FIGURE 2 | Transformation of the peritoneum with time on PD treatment with neutral pH, low GDP PD fluids. Blood microvessel density substantially increases within few months of PD. It is closely correlated with endothelial surface area, which presents the primary barrier for transport across the peritoneal dialysis membrane. Percentage of patients with substantial inflammatory cell infiltration and EMT increases with time on PD. VEGF signaling is particularly induced within the first year of PD, the TGF- $\beta$ signaling cascade (pSMAD) activation is delayed but remains high during long-term treatment (Schaefer et al., 2018).

accompanied by induction of VEGF- and TGF- $\beta$-induced SMAD phosphorylation, by EMT and inflammatory cells invasion (Schaefer et al., 2018) (Figure 2). This first study looking in detail in a larger number of patients into early and long term induced peritoneal changes and applying digital imaging analysis suggests that the assumption of significantly improved biocompatibility with neutral $\mathrm{pH}$, low GDP fluids cannot be maintained (Blake, 2018). Still, conclusions need to be drawn with caution, and comparison with high GPD fluids is difficult. Children are uniquely suited for the analysis of specific CKD- and PD-related pathomechanisms, since, different from adults, they mostly suffer from underlying diseases not affecting the peritoneum (Harambat et al., 2012) and they are largely free of lifestyle and aging-related tissue damage. On the other hand, findings cannot necessarily be transferred altogether to the adult $\mathrm{PD}$ population. Angiogenesis may be regulated differently in growing children, and factors absent in children may have an impact on peritoneal pathomechanisms in elderly PD patients. Neutral pH, low GDP fluids have been recommended by the European Pediatric Dialysis Working Group in 2011 (Schmitt et al., 2011), and the majority of European children are now treated with low GDP fluids. PD vintage and body surface area adjusted dialytic glucose exposure matched comparison with high GDP fluid treatment thus far has been limited to a total of 30 children. After 1 year of PD, children on high GDP PD had a higher degree of vasculopathy and more submesothelial thickening (Schaefer et al., 2016b). Similar findings were reported in 24 adult Japanese patients on PD for about 4.5 years. Peritoneal AGE accumulation, submesothelial thickening, and vasculopathy were less severe with low GDP usage (Kawanishi et al., 2013). In a subsequent study from the same group including additional patients, the protective effect of low GDP fluid on vasculopathy was reconfirmed (Hamada et al., 2015). Del Peso et al. (2016) compared 23 low and 23 high GDP PD-treated patients matched for PD vintage, and the mean treatment duration was 2 years. The mesothelial cell layer was better preserved, and vasculopathy was less pronounced in the patients on low GDP PD. In children, better preservation of the mesothelium cell layer could not be demonstrated, possibly due to the fragility of the pediatric samples and related processing artifacts. Altogether, these findings suggest distinct benefits of second over first-generation PD fluids, but higher patient numbers are needed to draw firm conclusions, at best in combination with functional data. 
No peritoneal tissues have been obtained from patients on amino acids or icodextrin solutions, clinical trials, however, suggest better preservation of the peritoneal transporter status when icodextrin solution is added to glucose-based high GDP regime (Davies et al., 2005).

In order to improve PD fluid biocompatibility, an in-depth understanding of molecular mechanisms of PD-induced membrane transformation and of related systemic effects of $\mathrm{PD}$ is required. Derived surrogate biomarkers of PD-induced pathomechanisms may allow predicting individual PD patient prognosis at an early stage and to guide dialysis therapy and establish therapeutic interventions. Up to now in clinical practice, PD biomarkers are largely limited to effluent cell count and cell differential. A number of potential surrogate parameters of peritoneal pathophysiology are on the horizon but still far from being established in clinical routine (Aufricht et al., 2017).

\section{MOLECULAR MECHANISMS OF PD-INDUCED PERITONEAL TRANSFORMATION}

Progressive destruction of the mesothelial cell layer, angiogenesis, and fibrosis and ultimately (life-threatening) peritoneal sclerosis (EPS) are due to an array of molecular mechanisms, which interact with each other. Peritoneal vessel density predicts peritoneal solute transport and overshooting vessel formation reduces ultrafiltration capacity, unless major fibrosis has developed, which reduces the osmotic conductance of glucose (Krediet et al., 2000). Experimental and human biopsy studies not only related peritoneal VEGF synthesis to peritoneal angiogenesis (De Vriese et al., 2001; Schaefer et al., 2018) but also shedded light on further aspects of the angiogenic machinery. Monoclonal VEGF antibody bevacizumab inhibits peritoneal angiogenesis and fibrosis in response to chlorhexidine (Ada et al., 2015). TNP-470, an endothelial cell cycle, and tumor angiogenesis inhibitor decreased peritoneal VEGF expression, EMT, vessel density, and fibrosis (Yoshio et al., 2004). Administration of endothelin-1 receptor antagonists in mice attenuated $\mathrm{PD}$-induced EMT, angiogenesis, fibrosis, and peritoneal functional decline (Busnadiego et al., 2015). Similar findings were obtained for endostatin, an endothelial cell proliferation and migration inhibitor, in a mouse model of EPS (Tanabe et al., 2007) and for intraperitoneal rho-kinase inhibition in a rat model of peritoneal fibrosis (Peng et al., 2013). Rapamycin decreased mesothelial cell VEGF synthesis and VEGF-C and VEGF-D release in vitro; combined PD and rapamycin treatment in mice reduced peritoneal EMT and thickening and submesothelial blood and lymphatic vessel proliferation as compared with mice exposed to PD fluid only (Gonzalez-Mateo et al., 2015). Addition of Tie2 fusion protein sTie2/Fc blocking Angiopoietin 2 downstream signaling to PD fluid infused once daily in uremic mice dose dependently reduces PD-induced peritoneal angiopoietin 2 synthesis and peritoneal hypervascularization (Xiao et al., 2013). Thus, several different interventions within the angiogenic signaling cascades can substantially reduce $\mathrm{PD}$-induced peritoneal membrane transformation. Thus far, however, such approaches have not been tested in the clinical setting of PD.
While experimental studies clearly demonstrated reduction of peritoneal angiogenesis with low compared to high GDP fluids (Mortier et al., 2004, 2005), the role of the buffer compound is less clear. In vitro, bicarbonate-buffered low GDP fluid induced less endothelial tube formation than the respective lactate-based fluid, due to an increase in angiopoietin 1/2 ratio, that is, a shift towards vessel maturation, and tyrosine kinase receptor (TEK) translocation to the endothelial cell membrane, where it co-localized with vascularendothelial cadherin, which stabilizes vessels (Eich et al., 2017). TEK plays a pivotal role in the regulation of sprouting and maturation of the vessels (Eklund and Saharinen, 2013). The finding was supported by a larger cross-sectional area of peritoneal vessels in eight bicarbonate fluid treated, peritonitis free children, as compared to the vessel area in age and glucose exposure matched children treated with the respective second-generation lactate PD fluid. Vessel size is an indicator of maturation (Suri et al., 1998). Up to now, only one, small size randomized trial comparing lactate and bicarbonatebuffered, neutral $\mathrm{pH}$, low GDP fluids has been accomplished and in line with the experimental findings - demonstrated better preservation of ultrafiltration achieved per gram of dialytic glucose exposure and body surface area in pediatric patients over 10 months with the bicarbonate fluid (Schmitt et al., 2013).

PD fluid toxicity induced early and pronounced peritoneal inflammation involving invasion of the PD membrane with macrophages and leucocytes, and inflammatory cytokine release is another major driver of structural and functional deterioration (Lambie et al., 2013, 2016; Schaefer et al., 2018). IL-6 is secreted by mesothelial cells after induction by IL- $1 ß$ and TNF- $\alpha$ (Topley et al., 1993). Individual differences in dialysate IL-6 concentrations have been linked to genetic polymorphisms (Siddique et al., 2015). In vitro and in mice, IL-6 was linked to VEGF production and thus angiogenesis via STAT3 and SP4 transcriptional factors (Catar et al., 2017); effluent IL-6 and VEGF concentrations are correlated (PecoitsFilho et al., 2002). In PD patients, dialysate concentrations of the proinflammatory cytokine IL- 6 are associated not only with higher peritoneal transporter status, i.e., faster solute and toxin removal, but also with ultrafiltration decline and protein loss (Lambie et al., 2013). In experimental PD, the anti-inflammatory Cox- 2 inhibitor, celecoxib, reduced peritoneal inflammation, angiogenesis, and fibrosis and preserved peritoneal membrane function (Fabbrini et al., 2009).

Another key element of peritoneal membrane transformation is epithelial (mesothelial) to mesenchymal transition (EMT), i.e., migration of mesothelial cells into the submesothelium and transition to a myofibroblast cell type. Lineage tracing studies furthermore suggest that myofibroblasts may also be derived from type I collagen-producing submesothelial fibroblasts (Chen et al., 2014). EMT is triggered by profibrotic and inflammatory stimuli cytokines (Yanez-Mo et al., 2003; Margetts et al., 2005; Loureiro et al., 2011; Bowen et al., 2013). Myofibroblasts secrete inflammatory, proangiogenic, and profibrotic cytokines and extracellular matrix components (Aroeira et al., 2007). In CKD5 patients, only single isolated EMT cells are present in the submesothelium, but their numbers rapidly increase with PD (Schaefer et al., 2018). In multivariate analysis, peritoneal EMT was independently associated with submesothelial thickness and with the microvessel number per mm tissue section. In experimental PD, EMT and associated peritoneal membrane damage can be inhibited by intraperitoneal 
BMP-7, antagonizing TGF- $\beta$ signaling (Loureiro et al., 2010). TGF- $\beta$ signaling again is centrally involved in the peritoneal fibrotic process as shown in various animal models of PD (Margetts et al., 2001) and in humans (Zhou et al., 2016; Schaefer et al., 2018). TGF- $\beta$ is secreted by resident (myo-) fibroblasts, with different fibroblast subgroups having different profibrotic properties. Glycopeptide Thy1-positive fibroblasts exhibit particular profibrotic and myofibroblast features (Kawka et al., 2017). MicroRNA (miR) array studies identified miR-21 and miR-31 to be highly expressed and induced by TGF- $\beta$ in mesothelial cells and to correlate with mesenchymal transition in vitro. Micro ribonucleic acid-21 and miR-31 are upregulated in the peritoneum of PD patients, and their effluent concentrations are associated with icodextrin and low GDP fluid use and related to peritonitis count and effluent IFN- $\gamma$ concentration. Altogether these findings suggest a great potential of these miRs as biomarker for membrane change in patients receiving PD (Lopez-Anton et al., 2017), respective large size clinical trials are needed.

\section{SYSTEMIC IMPACT OF PD FLUID BIOINCOMPATIBILITY}

Rather than mitigating CKD-associated pathomechanisms, such as inflammatory, carbonyl, and oxidative stress, $\mathrm{PD}$, while partially replacing renal function, adds additional risk factors. CKD-associated vasculopathy, prevalent even in young CKD patients, is further accelerated by PD. Potential pathomechanisms include the peritoneal glucose uptake, the additional GDP, and consequent AGE load and $\mathrm{PD}$-associated inflammation. In a cohort of almost 1,000 PD patients, intraperitoneal inflammation was the most important determinant of peritoneal solute transport but did not affect patient survival (Lambie et al., 2013). In contrast, systemic inflammation associated with comorbidity and independently predicted patient survival, suggesting independent peritoneal and systemic processes being active. Other studies point to a strong link between PD treatment and vasculopathy. Whole exome expression analyses of omental arterioles isolated from children with normal renal function, with CKD5D and while on low GDP PD revealed activation of metabolic processes in CKD5D arterioles and of inflammatory, immunologic, and stress-response cascades in arterioles of PD patients. The latter exhibited particular upregulation of the complement system and respective regulatory pathways, with concordant findings at the proteomic level. In independent validation cohorts, PD specimens had the highest abundance of omental and parietal arteriolar C1q, C3d, terminal complement complex and of phosphorylated SMAD2/3, a downstream effector of TGF- $\beta$. Furthermore, in the PD parietal arterioles, $\mathrm{C} 1 \mathrm{q}$ and terminal complement complex abundance correlated with the level of dialytic glucose exposure, the abundance of phosphorylated SMAD2/3, and the degree of vasculopathy (Bartosova et al., 2018). The close correlation of vascular TGF- $\beta$-induced SMAD2/3 phosphorylation and the severity of vasculopathy is supported by recent genome wide association, and systems biology studies identified the TGF- $\beta$ SMAD pathway to be strongly associated with coronary artery disease (Zeng et al., 2016). The analysis of small arteries and precapillary arterioles at least $1 \mathrm{~mm}$ below the mesothelial surface and thus beyond the PD penetration level (Stachowska-Pietka et al.,
2012) is of particular interest because they control peripheral resistance and microcirculation. Vasculopathy in this part of the arterial tree predicts left ventricular hypertrophy and cardiovascular events in hypertensive patients (Rizzoni et al., 2003; De Ciuceis et al., 2007). Concentrations of effluent complement protein have been linked to overall mortality in PD patients (Zelek et al., 2016).

\section{NOVEL PD FLUID PROTOTYPES}

Severe peritoneal damage still observed with low GDP fluids suggests that glucose per se has a major detrimental effect and that glucose sparing should mitigate PD-associated sequelae. Adding icodextrin and amino acid solution to a glucose-based PD regime improved glycated hemoglobin and lipid profile as compared to the glucose only PD regime, but deaths and serious adverse events, including several related to extracellular fluid volume expansion, have been reported to increase in the intervention group (Li et al., 2013). PD fluids with lower sodium concentration increased sodium removal and improved blood pressure but accelerated residual renal function decline (Blake, 2016; Rutkowski et al., 2016). In a small size crossover trial in adults and a pilot study in children, adapted automated PD, i.e., combining sequential short- and longer-dwell exchanges, with small and large dwell volumes, resulted in higher solute and fluid removal as compared to the standard regime with comparable dialysate fluid turn over and dialysis time (Fischbach et al., 2016). This concept awaits validation in extended clinical trials.

Replacing glucose by novel osmotic agents is a promising way to go in order to improve PD fluid biocompatibility. About 3.5\% taurine-based PD fluid achieved equivalent ultrafiltration as glucose-based PD fluid and induced less mesothelial and fibroblastlike cell proliferation in rats (Nishimura et al., 2009). Hyperbranched polyglycerol containing PD fluid achieved similar solute and water transport rates in rats and induced less peritoneal membrane damage (Mendelson et al., 2013; Du et al., 2016), but data on the metabolism of polyglycerol in plasma and ramifications of plasma accumulation and tissue disposition with long-term use are scant. A recent study in obese type 2 diabetic ZSF1 rats over 3 months suggests less systemic adverse effects on the kidneys and the plasma oxidative status with hyperbranched polyglycerol fluid as compared to second-generation and icodextrin PD fluid (La Han et al., 2018).

A different approach to more biocompatibility PD fluids is addition of protective compounds counteracting peritoneal fluid toxicity (Figure 3). PD fluids result in cellular stress and also suppress the natural stress response mechanisms, e.g., exerted by heat shock proteins (HSP) (Macario and Conway de Macario, 2007). Glutamine, a non-essential amino acid, has been shown to restore the cellular stress response pathway HSP27/72, which is suppressed by PD fluids. Addition of the dipeptide alanyl-glutamine to first- and second-generation PD fluid improved mesothelial cell stress response and cell survival in vitro and in vivo (Kratochwill et al., 2012). In uremic rat and mouse models of PD, alanylglutamine reduced peritoneal thickness, and angiogenesis, and peritoneal $\alpha$ SMA, IL-17, TGF- $\beta$, and IL-6 (Ferrantelli et al., 2016). In a first clinical trial, effluent cell HSP72 expression was increased following a 4-h dwell with alanyl-glutamine supplemented firstgeneration PD fluid, and the effluent increased TNF-alpha release 


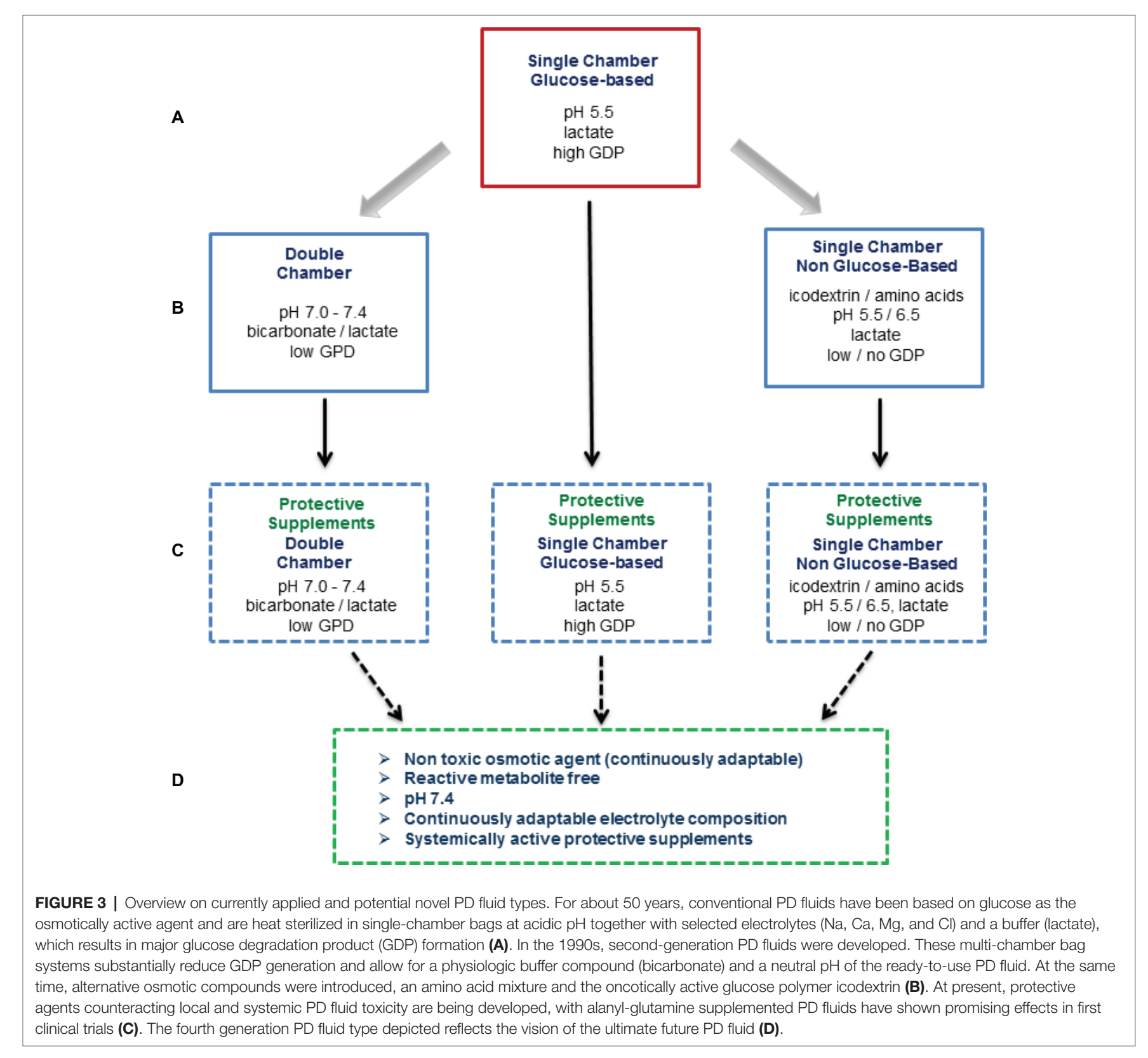

from LPS-stimulated peripheral blood mononuclear cells as compared to non-supplemented PD fluid. In post peritonitis patients, IL-6 and IL-8 effluent concentrations were reduced (Kratochwill et al., 2016). In a subsequent randomized crossover study, 41 patients were treated with alanyl-glutamine supplemented second-generation PD fluid over a period of 8 weeks each. Intraperitoneal alanyl-glutamine increased CA-125 appearance rate and effluent cell LPS-stimulated IL- 6 release, and the peritoneal transport of uric acid, phosphate, and potassium was higher and the peritoneal protein loss was reduced (Vychytil et al., 2018). These studies demonstrate significant benefits of alanyl-glutamine enriched PD fluid on peritoneal membrane integrity, immune competence, and transport function. A phase 3 trial is now needed to translate these encouraging effects into hard clinical outcomes.
Experimental PD studies and a clinical pilot study in 4 patients suggest good tolerability of carnitine supplemented PD fluids and superior ultrafiltration than achieved with $2.5 \%$ glucose solutions, despite lower osmolarity of the carnitine-containing solution (Bonomini et al., 2011). Addition of L-carnitine to acidic, glucosebased PD fluids in 27 non-diabetic patients improved insulin sensitivity assessed by euglycemic hyperinsulinemic clamp studies (Bonomini et al., 2013).

Understanding the molecular mechanism of peritoneal transport, its regulation by $\mathrm{CKD}$ and $\mathrm{PD}$ and pharmacological modification should be another way to improve PD biocompatibility and efficacy. Peritoneal membrane function has been well described by the three pore model (Rippe, 1993). Thus far, only the molecular basis of the "ultra-small pores" could be identified in mice, 
- Glucose

- Reactive metabolites

- AGEs

- Drugs

- TGF-B, VEGF

- Inflammation

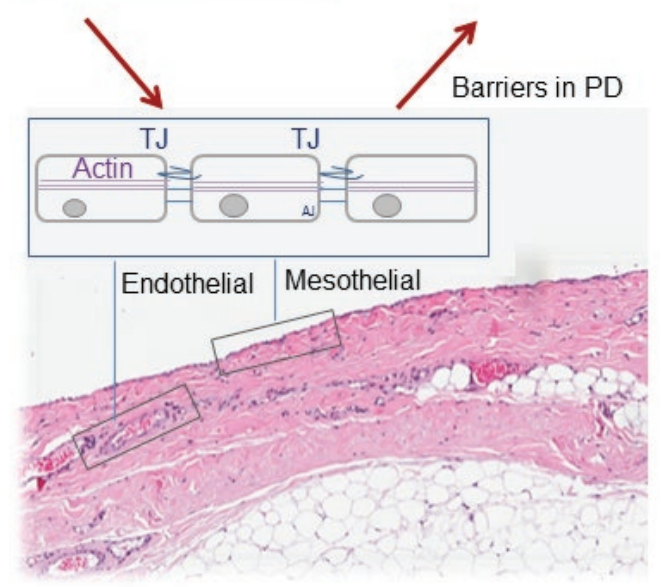

FIGURE 4 | Barriers for solute and water transport in PD. The endothelial and mesothelial cell monolayers form leaky membranes. Intercellular junctions define the selective permeability properties and thus paracellular bulk flow of small and large solutes together with water. An in-depth understanding of these key elements of PD should provide promising therapeutic targets to improve PD efficacy, biocompatibility, and sustainability.

aquaporin-1 (AQP-1), which exerts $50 \%$ of water transport (Ni et al., 2006). The molecular counterparts of "small pores" and "large pores," i.e., the mechanisms and regulatory machinery of the remaining $50 \%$ of the water transport, of solutes and sizedependent toxin removal are still unknown as are their modifications by uremia and PD. The primary transport barrier is the endothelium, and the role of the mesothelium is uncertain. Both capillary and mesothelial cell layers form leaky structures with similar in vitro transmembrane resistances but higher solute transport rates across the endothelial layer for 4-70 kDa dextrans (Horiuchi et al., 2009). Intercellular junctional complexes, including tight junctions, gap junctions, and desmosomes (Ito et al., 2000), define the selective permeability properties of the cell monolayer membrane and thus of bulk flow of small and large solutes together with water (Figure 4). Transcellular mechanisms imply transporters such as PiT for phosphate (Biber et al., 2013) and GLUT-1/2 and sodium glucose co-transporters such as SGLT-1/2 for glucose uptake (Debray-Garcia et al., 2016).

In-depth understanding of these key elements of peritoneal membrane transport function should provide promising therapeutic targets to improve PD efficacy, biocompatibility, and sustainability. Feasibility of this approach has been demonstrated for AQP-1. Dexamethasone twofold increased peritoneal AQP1 abundance and net ultrafiltration in rats without altering solute transport (Stoenoiu et al., 2003). AQP-1 agonist, AqF026, a chemical derivative of the aryl sulfonamide compound furosemide, increased water transport after 60 and $120 \mathrm{~min}$ of dwell time by 15-20\% (Yool et al., 2013). Although this strategy is promising to remove more water to achieve euvolemia, it does not increase salt removal and may aggravate thirst in patients. Still, these studies elegantly demonstrate that understanding and modulating the peritoneal water, salt, and toxin transport mechanisms are a promising area of research, hopefully resulting in major improvement of PD patient outcome.

\section{RÉSUMÉ}

The recent findings on histomorphological alterations of the peritoneum with so-called biocompatible, neutral $\mathrm{pH}$ PD fluids are disappointing and raised the question whether current concepts of PD fluid biocompatibility are "dead" (Blake, 2018). These sobering findings, however, have to be balanced against patientrelated outcome parameters. There is an early survival advantage for $\mathrm{PD}$ as compared to $\mathrm{HD}$, together with advantages of quality of life and autonomy to this home-based, cost-effective therapy. A recent analysis of the ERA-EDTA registry, which comprehensively collects real-life data from European countries, suggests an increasing 5-year patient survival benefit of PD over HD over the last 20 years (van de Luijtgaarden et al., 2016). In Europe, low GDP fluids have been licensed about 20 years ago and have increasingly been applied since then. At present, it is unclear that which factors contribute to these encouraging trends, but it is tempting to speculate that the lower systemic GDP and AGE load associated with low GDP PD fluid use (Zeier et al., 2003; Schmitt et al., 2007), an improved local host immune defense system possibly resulting in less frequent and less severe episodes of peritonitis (Johnson et al., 2012c), and the better preservation of residual renal function (Cho et al., 2014) play a significant role. Further large-scale patientrelated analyses are needed to delineate the specific PD-related risk factors and potential countermeasures, as well as the development of novel PD fluid types, which not only mitigate peritoneal damage but also systemic sequelae of chronic PD.

\section{AUTHOR CONTRIBUTIONS}

$\mathrm{MB}$ and CS performed the literature search and wrote the manuscript. Both authors approved the final version of the manuscript.

\section{FUNDING}

MB was supported by the European Training and Research in Peritoneal Dialysis (EuTRiPD) program, a project funded by the European Union within the Marie Curie Scheme (287813).

\section{ACKNOWLEDGMENTS}

We are grateful to colleagues who contributed over many years to the International (Pediatric) Peritoneal Biobank and the Tissue Bank of the National Center for Tumor Diseases (NCT, Heidelberg, Germany) and Institute of Pathology (Heidelberg University Hospital) for continuous support. 


\section{REFERENCES}

Ada, S., Ersan, S., Sifil, A., Unlu, M., Kolatan, E., Sert, M., et al. (2015). Effect of bevacizumab, a vascular endothelial growth factor inhibitor, on a rat model of peritoneal sclerosis. Int. Urol. Nephrol. 47, 2047-2051. doi: 10.1007/ s11255-015-1116-8

Aroeira, L. S., Aguilera, A., Sánchez-Tomero, J. A., Bajo, M. A., del Peso, G., JiménezHeffernan, J. A., et al. (2007). Epithelial to mesenchymal transition and peritoneal membrane failure in peritoneal dialysis patients: pathologic significance and potential therapeutic interventions. J. Am. Soc. Nephrol. 18, 2004-2013. doi: 10.1681/ASN.2006111292

Arung, W., Meurisse, M., and Detry, O. (2011). Pathophysiology and prevention of postoperative peritoneal adhesions. World J. Gastroenterol. 17, 4545-4553. doi: 10.3748/wjg.v17.i41.4545

Aufricht, C., Beelen, R., Eberl, M., Fischbach, M., Fraser, D., Jorres, A., et al. (2017). Biomarker research to improve clinical outcomes of peritoneal dialysis: consensus of the European Training and Research in Peritoneal Dialysis (EuTRiPD) network. Kidney Int. 92, 824-835. doi: 10.1016/j.kint.2017.02.037

Bajo, M. A., Perez-Lozano, M. L., Albar-Vizcaino, P., del Peso, G., Castro, M. J., Gonzalez-Mateo, G., et al. (2011). Low-GDP peritoneal dialysis fluid ('balance') has less impact in vitro and ex vivo on epithelial-to-mesenchymal transition (EMT) of mesothelial cells than a standard fluid. Nephrol. Dial. Transplant. 26, 282-291. doi: $10.1093 / \mathrm{ndt} / \mathrm{gfq} 357$

Bartosova, M., Schaefer, B., Bermejo, J. L., Tarantino, S., Lasitschka, F., MacherGoeppinger, S., et al. (2018). Complement activation in peritoneal dialysis-induced arteriolopathy. J. Am. Soc. Nephrol. 29, 268-282. doi: 10.1681/asn.2017040436

Bender, T. O., Witowski, J., Aufricht, C., Endemann, M., Frei, U., Passlick-Deetjen, J., et al. (2008). Biocompatibility of a bicarbonate-buffered amino-acid-based solution for peritoneal dialysis. Pediatr. Nephrol. 23, 1537-1543. doi: 10.1007/s00467-008-0834-x

Biber, J., Hernando, N., and Forster, I. (2013). Phosphate transporters and their function. Annu. Rev. Physiol. 75, 535-550. doi: 10.1146/annurev-physiol-030212-183748

Blackburn, S. C., and Stanton, M. P. (2014). Anatomy and physiology of the peritoneum. Semin. Pediatr. Surg. 23, 326-330. doi: 10.1053/j.sempedsurg.2014.06.002

Blake, P. G. (2016). Sodium levels in peritoneal dialysis solution: how low should we go? Am. J. Kidney Dis. 67, 719-721. doi: 10.1053/j.ajkd.2016.02.029

Blake, P. G. (2018). Is the peritoneal dialysis biocompatibility hypothesis dead? Kidney Int. 94, 246-248. doi: 10.1016/j.kint.2018.04.014

Bonomini, M., Di Liberato, L., Del Rosso, G., Stingone, A., Marinangeli, G., Consoli, A., et al. (2013). Effect of an L-carnitine-containing peritoneal dialysate on insulin sensitivity in patients treated with CAPD: a 4-month, prospective, multicenter randomized trial. Am. J. Kidney Dis. 62, 929-938. doi: 10.1053/j.ajkd.2013.04.007

Bonomini, M., Pandolfi, A., Di Liberato, L., Di Silvestre, S., Cnops, Y., Di Tomo, P., et al. (2011). L-carnitine is an osmotic agent suitable for peritoneal dialysis. Kidney Int. 80, 645-654. doi: 10.1038/ki.2011.117

Bowen, T., Jenkins, R. H., and Fraser, D. J. (2013). MicroRNAs, transforming growth factor beta-1, and tissue fibrosis. J. Pathol. 229, 274-285. doi: 10.1002/path.4119

Burkhardt, D., Bartosova, M., Schaefer, B., Grabe, N., Lahrmann, B., Nasser, H., et al. (2016). Reduced microvascular density in omental biopsies of children with chronic kidney disease. PLoS One 11:e0166050. doi: 10.1371/journal.pone.0166050

Busnadiego, O., Loureiro-Alvarez, J., Sandoval, P., Lagares, D., Dotor, J., Perez-Lozano, M. L., et al. (2015). A pathogenetic role for endothelin-1 in peritoneal dialysisassociated fibrosis. J. Am. Soc. Nephrol. 26, 173-182. doi: 10.1681/asn.2013070799

Catar, R., Witowski, J., Zhu, N., Lucht, C., Derrac Soria, A., Uceda Fernandez, J., et al. (2017). IL-6 trans-signaling links inflammation with angiogenesis in the peritoneal membrane. J. Am. Soc. Nephrol. 28, 1188-1199. doi: 10.1681/asn.2015101169

Chamorro, M., Carceller, F., Llanos, C., Rodriguez-Alvarino, A., Colmenero, C., and Burgueno, M. (1993). The effect of omental wrapping on nerve graft regeneration. Br. J. Plast. Surg. 46, 426-429. doi: 10.1016/0007-1226(93)90050-L

Chen, Y. T., Chang, Y. T., Pan, S. Y., Chou, Y. H., Chang, F. C., Yeh, P. Y., et al. (2014). Lineage tracing reveals distinctive fates for mesothelial cells and submesothelial fibroblasts during peritoneal injury.J.Am. Soc. Nephrol.25, 2847-2858. doi:10.1681/asn.2013101079

Cho, Y., Johnson, D. W., Badve, S., Craig, J. C., Strippoli, G. F., and Wiggins, K. J. (2013). Impact of icodextrin on clinical outcomes in peritoneal dialysis: a systematic review of randomized controlled trials. Nephrol. Dial. Transplant. 28, 1899-1907. doi: 10.1093/ndt/gft050

Cho, Y., Johnson, D. W., Craig, J. C., Strippoli, G. F., Badve, S. V., and Wiggins, K. J. (2014). Biocompatible dialysis fluids for peritoneal dialysis. Cochrane Database Syst. Rev. 3, 1465-1858. Cd007554. doi: 10.1002/14651858.CD007554.pub2
Combet, S., Miyata, T., Moulin, P., Pouthier, D., Goffin, E., and Devuyst, O. (2000) Vascular proliferation and enhanced expression of endothelial nitric oxide synthase in human peritoneum exposed to long-term peritoneal dialysis. J. Am. Soc. Nephrol. 11, 717-728.

Contreras-Velazquez, J. C., Soto, V., Jaramillo-Rodriguez, Y., Samaniego-Rios, L. I., Quinones-Perez, V., Avila, M., et al. (2008). Clinical outcomes and peritoneal histology in patients starting peritoneal dialysis are related to diabetic status and serum albumin levels. Kidney Int. Suppl. (108), S34-S41. doi: 10.1038/sj.ki.5002599

Davies, S. J., Brown, E. A., Frandsen, N. E., Rodrigues, A. S., Rodriguez-Carmona, A., Vychytil, A., et al. (2005). Longitudinal membrane function in functionally anuric patients treated with APD: data from EAPOS on the effects of glucose and icodextrin prescription. Kidney Int. 67, 1609-1615. doi: 10.1111/j.1523-1755.2005.00243.x

Davies, S. J., Phillips, L., Griffiths, A. M., Russell, L. H., Naish, P. F., and Russell, G. I. (1998). What really happens to people on long-term peritoneal dialysis? Kidney Int. 54, 2207-2217. doi: 10.1046/j.1523-1755.1998.00180.x

Davies, S. J., Phillips, L., Naish, P. F., and Russell, G. I. (2001). Peritoneal glucose exposure and changes in membrane solute transport with time on peritoneal dialysis. J. Am. Soc. Nephrol. 12, 1046-1051.

Davies, S. J., Yewdall, V. M., Ogg, C. S., and Cameron, J. S. (1990). Peritoneal defence mechanisms and Staphylococcus aureus in patients treated with continuous ambulatory peritoneal dialysis (CAPD). Perit. Dial. Int. 10, 135-140.

De Ciuceis, C., Porteri, E., Rizzoni, D., Rizzardi, N., Paiardi, S., Boari, G. E., et al. (2007). Structural alterations of subcutaneous small-resistance arteries may predict major cardiovascular events in patients with hypertension. Am. J. Hypertens. 20, 846-852. doi: 10.1016/j.amjhyper.2007.03.016

de Jager, D. J., Grootendorst, D. C., Jager, K. J., van Dijk, P. C., Tomas, L. M., Ansell, D., et al. (2009). Cardiovascular and noncardiovascular mortality among patients starting dialysis. JAMA 302, 1782-1789. doi: 10.1001/jama.2009.1488

De Vriese, A. S., Tilton, R. G., Stephan, C. C., and Lameire, N. H. (2001). Vascular endothelial growth factor is essential for hyperglycemia-induced structural and functional alterations of the peritoneal membrane. J. Am. Soc. Nephrol. 12, 1734-1741.

Debray-Garcia, Y., Sanchez, E. I., Rodriguez-Munoz, R., Venegas, M. A., Velazquez, J., and Reyes, J. L. (2016). Diabetes and exposure to peritoneal dialysis solutions alter tight junction proteins and glucose transporters of rat peritoneal mesothelial cells. Life Sci. 161, 78-89. doi: 10.1016/j.lfs.2016.07.018

Del Peso, G., Jimenez-Heffernan, J. A., Selgas, R., Remon, C., Ossorio, M., FernandezPerpen, A., et al. (2016). Biocompatible dialysis solutions preserve peritoneal mesothelial cell and vessel wall integrity. A case-control study on human biopsies. Perit. Dial. Int. 36, 129-134. doi: 10.3747/pdi.2014.00038

Dombros, N. V., Prutis, K., Tong, M., Anderson, G. H., Harrison, J., Sombolos, K., et al. (1990). Six-month overnight intraperitoneal amino-acid infusion in continuous ambulatory peritoneal dialysis (CAPD) patients-no effect on nutritional status. Perit. Dial. Int. 10, 79-84.

Dousdampanis, P., Musso, C. G., and Trigka, K. (2018). Icodextrin and peritoneal dialysis: advantages and new applications. Int. Urol. Nephrol. 50, 495-500. doi: 10.1007/s11255-017-1647-2

Du, C., Mendelson, A. A., Guan, Q., Dairi, G., Chafeeva, I., da Roza, G., et al. (2016). Hyperbranched polyglycerol is superior to glucose for long-term preservation of peritoneal membrane in a rat model of chronic peritoneal dialysis. J. Transl. Med. 14:338. doi: 10.1186/s12967-016-1098-z

Eich, G., Bartosova, M., Tischer, C., Wlodkowski, T. T., Schaefer, B., Pichl, S., et al. (2017). Bicarbonate buffered peritoneal dialysis fluid upregulates angiopoietin-1 and promotes vessel maturation. PLoS One 12:e0189903. doi: 10.1371/journal.pone.0189903

Eklund, L., and Saharinen, P. (2013). Angiopoietin signaling in the vasculature. Exp. Cell Res. 319, 1271-1280. doi: 10.1016/j.yexcr.2013.03.011

Erixon, M., Wieslander, A., Linden, T., Carlsson, O., Forsback, G., Svensson, E., et al. (2006). How to avoid glucose degradation products in peritoneal dialysis fluids. Perit. Dial. Int. 26, 490-497.

Fabbrini, P., Schilte, M. N., Zareie, M., ter Wee, P. M., Keuning, E. D., Beelen, R. H., et al. (2009). Celecoxib treatment reduces peritoneal fibrosis and angiogenesis and prevents ultrafiltration failure in experimental peritoneal dialysis. Nephrol. Dial. Transplant. 24, 3669-3676. doi: 10.1093/ndt/gfp384

Fagiani, E., and Christofori, G. (2013). Angiopoietins in angiogenesis. Cancer Lett. 328, 18-26. doi: 10.1016/j.canlet.2012.08.018

Farhat, K., Douma, C. E., Ferrantelli, E., Ter Wee, P. M., Beelen, R. H. J., and van Ittersum, F. J. (2017). Effects of conversion to a bicarbonate/lactate-buffered, neutral$\mathrm{pH}$, low-GDP PD regimen in prevalent PD: a 2-year randomized clinical trial. Perit. Dial. Int. 37, 273-282. doi: 10.3747/pdi.2015.00031 
Feneberg, R., Schaefer, F., Zieger, B., Waldherr, R., Mehls, O., and Scharer, K. (1998). Percutaneous renal biopsy in children: a 27-year experience. Nephron 79, 438-446. doi: $10.1159 / 000045090$

Ferrantelli, E., Liappas, G., Vila Cuenca, M., Keuning, E. D., Foster, T. L., Vervloet, M. G., et al. (2016). The dipeptide alanyl-glutamine ameliorates peritoneal fibrosis and attenuates IL-17 dependent pathways during peritoneal dialysis. Kidney Int. 89, 625-635. doi: 10.1016/j.kint.2015.12.005

Fischbach, M., Schmitt, C. P., Shroff, R., Zaloszyc, A., and Warady, B. A. (2016). Increasing sodium removal on peritoneal dialysis: applying dialysis mechanics to the peritoneal dialysis prescription. Kidney Int. 89, 761-766. doi: 10.1016/j. kint.2015.12.032

Goldsmith, H. S. (2001). Role of the omentum in the treatment of Alzheimer's disease. Neurol. Res. 23, 555-564. doi: 10.1179/016164101101198893

Gonzalez-Mateo, G. T., Aguirre, A. R., Loureiro, J., Abensur, H., Sandoval, P., SanchezTomero, J. A., et al. (2015). Rapamycin protects from type-I peritoneal membrane failure inhibiting the angiogenesis, lymphangiogenesis, and Endo-MT. Biomed. Res. Int. 2015:989560. doi: 10.1155/2015/989560

Grossin, N., Wautier, M. P., Wautier, J. L., Gane, P., Taamma, R., and Boulanger, E. (2006). Improved in vitro biocompatibility of bicarbonate-buffered peritoneal dialysis fluid. Perit. Dial. Int. 26, 664-670.

Grupp, A., Kimmel, M., Fritz, P., Voggenreiter, B., Stoltzing, H., Kuhlmann, U., et al. (2007). The expression patterns of peritoneal defensins. Perit. Dial. Int. 27, 654-662.

Haag-Weber, M., Kramer, R., Haake, R., Islam, M. S., Prischl, F., Haug, U., et al. (2010). Low-GDP fluid (Gambrosol trio) attenuates decline of residual renal function in PD patients: a prospective randomized study. Nephrol. Dial. Transplant. 25, 2288-2296. doi: 10.1093/ndt/gfq087

Haas, S., Schmitt, C. P., Arbeiter, K., Bonzel, K. E., Fischbach, M., John, U., et al. (2003). Improved acidosis correction and recovery of mesothelial cell mass with neutral-pH bicarbonate dialysis solution among children undergoing automated peritoneal dialysis. J. Am. Soc. Nephrol. 14, 2632-2638. doi: 10.1097/01.asn.0000086475.83211.df

Hall, J. C., Heel, K. A., Papadimitriou, J. M., and Platell, C. (1998). The pathobiology of peritonitis. Gastroenterology 114, 185-196. doi: 10.1016/S0016-5085(98)70646-8

Hamada, C., Honda, K., Kawanishi, K., Nakamoto, H., Ito, Y., Sakurada, T., et al. (2015). Morphological characteristics in peritoneum in patients with neutral peritoneal dialysis solution. J. Artif. Organs 18, 243-250. doi: 10.1007/s10047-015-0822-4

Harambat, J., van Stralen, K. J., Kim, J. J., and Tizard, E. J. (2012). Epidemiology of chronic kidney disease in children. Pediatr. Nephrol. 27, 363-373. doi: 10.1007/ s00467-011-1939-1

Hills, B. A., Burke, J. R., and Thomas, K. (1998). Surfactant barrier lining peritoneal mesothelium: lubricant and release agent. Perit. Dial. Int. 18, 157-165.

Ho-dac-Pannekeet, M. M., Koopmans, J. G., Struijk, D. G., and Krediet, R. T. (1997). Restriction coefficients of low molecular weight solutes and macromolecules during peritoneal dialysis. Adv. Perit. Dial. 13, 72-76.

Holmdahl, L., Eriksson, E., Al-Jabreen, M., and Risberg, B. (1996). Fibrinolysis in human peritoneum during operation. Surgery 119, 701-705. doi: 10.1016/ S0039-6060(96)80196-6

Horiuchi, T., Matsunaga, K., Banno, M., Nakano, Y., Nishimura, K., Hanzawa, C., et al. (2009). HPMCs induce greater intercellular delocalization of tight junctionassociated proteins due to a higher susceptibility to $\mathrm{H} 2 \mathrm{O} 2$ compared with HUVECs. Perit. Dial. Int. 29, 217-226.

Isaza-Restrepo, A., Martin-Saavedra, J. S., Velez-Leal, J. L., Vargas-Barato, F., and Riveros-Duenas, R. (2018). The peritoneum: beyond the tissue-a review. Front. Physiol. 9:738. doi: 10.3389/fphys.2018.00738

Ito, T., Yorioka, N., Yamamoto, M., Kataoka, K., and Yamakido, M. (2000). Effect of glucose on intercellular junctions of cultured human peritoneal mesothelial cells. J. Am. Soc. Nephrol. 11, 1969-1979. doi: 10.1159/000069547

Jiang, J., Chen, P., Chen, J., Yu, X., Xie, D., Mei, C., et al. (2012). Accumulation of tissue advanced glycation end products correlated with glucose exposure dose and associated with cardiovascular morbidity in patients on peritoneal dialysis. Atherosclerosis 224, 187-194. doi: 10.1016/j.atherosclerosis.2012.06.022

Johnson, D. W., Brown, F. G., Clarke, M., Boudville, N., Elias, T. J., Foo, M. W., et al. (2012a). Effects of biocompatible versus standard fluid on peritoneal dialysis outcomes. J. Am. Soc. Nephrol. 23, 1097-1107. doi: 10.1681/asn.2011121201

Johnson, D. W., Brown, F. G., Clarke, M., Boudville, N., Elias, T. J., Foo, M. W., et al. (2012b). The effect of low glucose degradation product, neutral $\mathrm{pH}$ versus standard peritoneal dialysis solutions on peritoneal membrane function: the balANZ trial. Nephrol. Dial. Transplant. 27, 4445-4453. doi: 10.1093/ndt/gfs314
Johnson, D. W., Brown, F. G., Clarke, M., Boudville, N., Elias, T. J., Foo, M. W., et al. (2012c). The effects of biocompatible compared with standard peritoneal dialysis solutions on peritonitis microbiology, treatment, and outcomes: the balANZ trial. Perit. Dial. Int. 32, 497-506. doi: 10.3747/pdi.2012.00052

Kawanishi, K., Honda, K., Tsukada, M., Oda, H., and Nitta, K. (2013). Neutral solution low in glucose degradation products is associated with less peritoneal fibrosis and vascular sclerosis in patients receiving peritoneal dialysis. Perit. Dial. Int. 33, 242-251. doi: 10.3747/pdi.2011.00270

Kawka, E., Witowski, J., Bartosova, M., Catar, R., Rudolf, A., Philippe, A., et al. (2017). Thy-1(+/-) fibroblast subsets in the human peritoneum. Am. J. Physiol. Renal Physiol. 313, F1116-F1123. doi: 10.1152/ajprenal.00274.2017

Kim, S. G., Kim, S., Hwang, Y. H., Kim, K., Oh, J. E., Chung, W., et al. (2008). Could solutions low in glucose degradation products preserve residual renal function in incident peritoneal dialysis patients? A 1-year multicenter prospective randomized controlled trial (Balnet Study). Perit. Dial. Int. 28(Suppl 3), S117-S122.

Kramer, A., Pippias, M., Noordzij, M., Stel, V. S., Afentakis, N., Ambuhl, P. M., et al. (2018). The European Renal Association - European Dialysis and Transplant Association (ERA-EDTA) Registry Annual Report 2015: a summary. Clin. Kidney J. 11, 108-122. doi: 10.1093/ckj/sfx149

Kratochwill, K., Boehm, M., Herzog, R., Gruber, K., Lichtenauer, A. M., Kuster, L., et al. (2016). Addition of alanyl-glutamine to dialysis fluid restores peritoneal cellular stress responses - a first-in-man trial. PLoS One 11:e0165045. doi: 10.1371/ journal.pone.0165045

Kratochwill, K., Boehm, M., Herzog, R., Lichtenauer, A. M., Salzer, E., Lechner, M., et al. (2012). Alanyl-glutamine dipeptide restores the cytoprotective stress proteome of mesothelial cells exposed to peritoneal dialysis fluids. Nephrol. Dial. Transplant. 27, 937-946. doi: 10.1093/ndt/gfr459

Krediet, R. T., Lindholm, B., and Rippe, B. (2000). Pathophysiology of peritoneal membrane failure. Perit. Dial. Int. 20(Suppl 4), S22-S42.

Krediet, R. T., and Struijk, D. G. (2013). Peritoneal changes in patients on long-term peritoneal dialysis. Nat. Rev. Nephrol. 9, 419-429. doi: 10.1038/nrneph.2013.99

La Han, B., Guan, Q., Chafeeva, I., Mendelson, A. A., da Roza, G., Liggins, R., et al. (2018). Peritoneal and systemic responses of obese type II diabetic rats to chronic exposure to a hyperbranched polyglycerol-based dialysis solution. Basic Clin. Pharmacol. Toxicol. 123, 494-503. doi: 10.1111/bcpt.13038

Lambie, M., Chess, J., Donovan, K. L., Kim, Y. L., Do, J. Y., Lee, H. B., et al. (2013). Independent effects of systemic and peritoneal inflammation on peritoneal dialysis survival. J. Am. Soc. Nephrol. 24, 2071-2080. doi: 10.1681/asn.2013030314

Lambie, M. R., Chess, J., Summers, A. M., Williams, P. F., Topley, N., and Davies, S. J. (2016). Peritoneal inflammation precedes encapsulating peritoneal sclerosis: results from the GLOBAL Fluid Study. Nephrol. Dial. Transplant. 31, 480-486. doi: 10.1093/ndt/gfv440

Lemoine, L., Sugarbaker, P., and Van der Speeten, K. (2016). Pathophysiology of colorectal peritoneal carcinomatosis: role of the peritoneum. World J. Gastroenterol. 22, 7692-7707. doi: 10.3748/wjg.v22.i34.7692

Li, P. K., Culleton, B. F., Ariza, A., Do, J. Y., Johnson, D. W., Sanabria, M., et al. (2013). Randomized, controlled trial of glucose-sparing peritoneal dialysis in diabetic patients. J. Am. Soc. Nephrol. 24, 1889-1900. doi: 10.1681/asn.2012100987

Lopez-Anton, M., Lambie, M., Lopez-Cabrera, M., Schmitt, C. P., Ruiz-Carpio, V., Bartosova, M., et al. (2017). miR-21 promotes fibrogenesis in peritoneal dialysis. Am. J. Pathol. 187, 1537-1550. doi: 10.1016/j.ajpath.2017.03.007

Loureiro, J., Aguilera, A., Selgas, R., Sandoval, P., Albar-Vizcaíno, P., Pérez-Lozano, M.L., et al. (2011). Blocking TGF- $\beta 1$ protects the peritoneal membrane from dialysateinduced damage. J. Am. Soc. Nephrol. 22, 1682-1695. doi: 10.1681/ASN.2010111197

Loureiro, J., Schilte, M., Aguilera, A., Albar-Vizcaino, P., Ramirez-Huesca, M., PerezLozano, M. L., et al. (2010). BMP-7 blocks mesenchymal conversion of mesothelial cells and prevents peritoneal damage induced by dialysis fluid exposure. Nephrol. Dial. Transplant. 25, 1098-1108. doi: 10.1093/ndt/gfp618

Ma, C., Tarnuzzer, R. W., and Chegini, N. (1999). Expression of matrix metalloproteinases and tissue inhibitor of matrix metalloproteinases in mesothelial cells and their regulation by transforming growth factor-betal. Wound Repair Regen. 7, 477-485. doi: 10.1046/j.1524-475X.1999.00477.x

Macario, A. J., and Conway de Macario, E. (2007). Chaperonopathies and chaperonotherapy. FEBS Lett. 581, 3681-3688. doi: 10.1016/j.febslet.2007.04.030

Margetts, P. J., Bonniaud, P., Liu, L., Hoff, C. M., Holmes, C. J., West-Mays, J. A., et al. (2005). Transient overexpression of TGF-\{beta 1 induces epithelial mesenchymal transition in the rodent peritoneum. J. Am. Soc. Nephrol. 16, 425-436. doi: 10.1681/ ASN.2004060436 
Margetts, P. J., Kolb, M., Galt, T., Hoff, C. M., Shockley, T. R., and Gauldie, J. (2001). Gene transfer of transforming growth factor-betal to the rat peritoneum: effects on membrane function. J. Am. Soc. Nephrol. 12, 2029-2039.

Marshall, B. C., Santana, A., Xu, Q. P., Petersen, M. J., Campbell, E. J., Hoidal, J. R., et al. (1993). Metalloproteinases and tissue inhibitor of metalloproteinases in mesothelial cells. Cellular differentiation influences expression. J. Clin. Invest. 91, 1792-1799. doi: 10.1172/jci116390

Martikainen, T. A., Teppo, A. M., Gronhagen-Riska, C., and Ekstrand, A. V. (2005). Glucose-free dialysis solutions: inductors of inflammation or preservers of peritoneal membrane? Perit. Dial. Int. 25, 453-460.

McDonald, S. P., Marshall, M. R., Johnson, D. W., and Polkinghorne, K. R. (2009). Relationship between dialysis modality and mortality. J. Am. Soc. Nephrol. 20, 155-163. doi: 10.1681/asn.2007111188

Mehrotra, R., Devuyst, O., Davies, S. J., and Johnson, D. W. (2016). The current state of peritoneal dialysis. J. Am. Soc. Nephrol. 27, 3238-3252. doi: 10.1681/ asn.2016010112

Mendelson, A. A., Guan, Q., Chafeeva, I., da Roza, G. A., Kizhakkedathu, J. N., and Du, C. (2013). Hyperbranched polyglycerol is an efficacious and biocompatible novel osmotic agent in a rodent model of peritoneal dialysis. Perit. Dial. Int. 33, 15-27. doi: 10.3747/pdi.2012.00148

Morelle, J., Sow, A., Fustin, C. A., Fillee, C., Garcia-Lopez, E., Lindholm, B., et al. (2018). Mechanisms of crystalloid versus colloid osmosis across the peritoneal membrane. J. Am. Soc. Nephrol. 29, 1875-1886. doi: 10.1681/asn.2017080828

Moriishi, M., and Kawanishi, H. (2008). Icodextrin and intraperitoneal inflammation. Perit. Dial. Int. 28(Suppl 3), S96-S100.

Mortier, S., De Vriese, A. S., McLoughlin, R. M., Topley, N., Schaub, T. P., PasslickDeetjen, J., et al. (2003). Effects of conventional and new peritoneal dialysis fluids on leukocyte recruitment in the rat peritoneal membrane. J. Am. Soc. Nephrol. 14, 1296-1306. doi: 10.1097/01.asn.0000060681.91079.30

Mortier, S., Faict, D., Lameire, N. H., and De Vriese, A. S. (2005). Benefits of switching from a conventional to a low-GDP bicarbonate/lactate-buffered dialysis solution in a rat model. Kidney Int. 67, 1559-1565. doi: 10.1111/j.1523-1755.2005.00237.x

Mortier, S., Faict, D., Schalkwijk, C. G., Lameire, N. H., and De Vriese, A. S. (2004). Long-term exposure to new peritoneal dialysis solutions: effects on the peritoneal membrane. Kidney Int. 66, 1257-1265. doi: 10.1111/j.1523-1755.2004.00879.x

Na kao, M., Yamamoto, I., Maruyama, Y., Morishita, M., Nakashima, A., Matsuo, N., et al. (2017). Risk factors for encapsulating peritoneal sclerosis: analysis of a 36-year experience in a University Hospital. Nephrology (Carlton) 22, 907-912. doi: $10.1111 /$ nep. 12911

Nataatmadja, M., Johnson, D. W., Pascoe, E. M., Darssan, D., Hawley, C. M., and Cho, Y. (2018). Associations between peritoneal glucose exposure, glucose degradation product exposure, and peritoneal membrane transport characteristics in peritoneal dialysis patients: secondary analysis of the balANZ trial. Perit. Dial. Int. 38, 349-355. doi: $10.3747 /$ pdi.2017.00223

Ni, J., Verbavatz, J. M., Rippe, A., Boisde, I., Moulin, P., Rippe, B., et al. (2006). Aquaporin-1 plays an essential role in water permeability and ultrafiltration during peritoneal dialysis. Kidney Int. 69, 1518-1525. doi: 10.1038/sj.ki.5000285

Nishimura, H., Ikehara, O., Naito, T., Higuchi, C., and Sanaka, T. (2009). Evaluation of taurine as an osmotic agent for peritoneal dialysis solution. Perit. Dial. Int. 29, 204-216.

Ortega, L. M., and Materson, B. J. (2011). Hypertension in peritoneal dialysis patients: epidemiology, pathogenesis, and treatment. J. Am. Soc. Hypertens. 5, 128-136. doi: 10.1016/j.jash.2011.02.004

Papapetropoulos, A., Garcia-Cardena, G., Madri, J. A., and Sessa, W. C. (1997). Nitric oxide production contributes to the angiogenic properties of vascular endothelial growth factor in human endothelial cells. J. Clin. Invest. 100, 3131-3139. doi: 10.1172/jci119868

Parikova, A., Zweers, M. M., Struijk, D. G., and Krediet, R. T. (2003). Peritoneal effluent markers of inflammation in patients treated with icodextrin-based and glucosebased dialysis solutions. Adv. Perit. Dial. 19, 186-190.

Pecoits-Filho, R., Araujo, M. R., Lindholm, B., Stenvinkel, P., Abensur, H., Romao, J. E. Jr., et al. (2002). Plasma and dialysate IL-6 and VEGF concentrations are associated with high peritoneal solute transport rate. Nephrol. Dial. Transplant. 17, 1480-1486. doi: 10.1093/ndt/17.8.1480

Peng, W., Zhou, Q., Ao, X., Tang, R., and Xiao, Z. (2013). Inhibition of Rho-kinase alleviates peritoneal fibrosis and angiogenesis in a rat model of peritoneal dialysis. Ren. Fail. 35, 958-966. doi: 10.3109/0886022x.2013.808565

Reimann, D., Dachs, D., Meye, C., and Gross, P. (2004). Amino acid-based peritoneal dialysis solution stimulates mesothelial nitric oxide production. Perit. Dial. Int. $24,378-384$.
Rippe, B. (1993). A three-pore model of peritoneal transport. Perit. Dial. Int. 13(Suppl 2), S35-S38.

Rippe, B. (2009). Peritoneal angiogenesis in response to dialysis fluid. Contrib. Nephrol. 163, 60-66. doi: 10.1159/000223781

Rizzoni, D., Porteri, E., Boari, G. E., De Ciuceis, C., Sleiman, I., Muiesan, M. L., et al. (2003). Prognostic significance of small-artery structure in hypertension. Circulation 108, 2230-2235. doi: 10.1161/01.cir.0000095031.51492.c5

Robinson, B. (1897). V. Observations upon the absorption of fluids by the peritoneum. Ann. Surg. 25, 332-350.

Rutkowski, B., Tam, P., van der Sande, F. M., Vychytil, A., Schwenger, V., Himmele, R., et al. (2016). Low-sodium versus standard-sodium peritoneal dialysis solution in hypertensive patients: a randomized controlled trial. Am. J. Kidney Dis. 67, 753-761. doi: 10.1053/j.ajkd.2015.07.031

Ryu, H. M., Oh, E. J., Park, S. H., Kim, C. D., Choi, J. Y., Cho, J. H., et al. (2012). Aquaporin 3 expression is up-regulated by TGF-betal in rat peritoneal mesothelial cells and plays a role in wound healing. Am. J. Pathol. 181, 2047-2057. doi: 10.1016/j. ajpath.2012.08.018

Schaefer, B., Bartosova, M., Macher-Goeppinger, S., Sallay, P., Voros, P., Ranchin, B., et al. (2018). Neutral $\mathrm{pH}$ and low-glucose degradation product dialysis fluids induce major early alterations of the peritoneal membrane in children on peritoneal dialysis. Kidney Int. 94, 419-429. doi: 10.1016/j.kint.2018.02.022

Schaefer, B., Bartosova, M., Macher-Goeppinger, S., Ujszaszi, A., Wallwiener, M., Nyarangi-Dix, J., et al. (2016a). Quantitative histomorphometry of the healthy peritoneum. Sci. Rep. 6, 21344. doi: 10.1038/srep21344

Schaefer, B., Bartosova, M., Taylan, C., VandeWalle, J., Querfeld, U., Krmar, R., et al. (2016b). The PD membrane microvasculature in uremia and PD-recent findings from the International Pediatric PD Biobank. Abstracts for the 17th IPNA Congress, Iguacu, Brazil, September 2016: oral presentations. Pediatr. Nephrol. 31, 1723-1764. doi: 10.1007/s00467-016-3466-6

Schmitt, C. P., and Aufricht, C. (2016). Is there such a thing as biocompatible peritoneal dialysis fluid? Pediatr. Nephrol. 32, 1835-1843. doi: 10.1007/s00467-016-3461-y

Schmitt, C. P., Bakkaloglu, S. A., Klaus, G., Schroder, C., Fischbach, M., and European Pediatric Dialysis Working Group (2011). Solutions for peritoneal dialysis in children: recommendations by the European Pediatric Dialysis Working Group. Pediatr. Nephrol. 26, 1137-1147. doi: 10.1007/s00467-011-1863-4

Schmitt, C. P., Haraldsson, B., Doetschmann, R., Zimmering, M., Greiner, C., Boswald, M., et al. (2002). Effects of pH-neutral, bicarbonate-buffered dialysis fluid on peritoneal transport kinetics in children. Kidney Int. 61, 1527-1536. doi: 10.1046/j.1523-1755.2002.00255.x

Schmitt, C. P., Nau, B., Gemulla, G., Bonzel, K. E., Holtta, T., Testa, S., et al. (2013). Effect of the dialysis fluid buffer on peritoneal membrane function in children. Clin. J. Am. Soc. Nephrol. 8, 108-115. doi: 10.2215/CJN.00690112

Schmitt, C. P., von Heyl, D., Rieger, S., Arbeiter, K., Bonzel, K. E., Fischbach, M., et al. (2007). Reduced systemic advanced glycation end products in children receiving peritoneal dialysis with low glucose degradation product content. Nephrol. Dial. Transplant. 22, 2038-2044. doi: 10.1093/ndt/gfm148

Siddique, I., Brimble, K. S., Walkin, L., Summers, A., Brenchley, P., Herrick, S., et al. (2015). Genetic polymorphisms and peritoneal membrane function. Perit. Dial. Int. 35, 517-529. doi: 10.3747/pdi.2014.00049

Stachowska-Pietka, J., Waniewski, J., Flessner, M. F., and Lindholm, B. (2012). Computer simulations of osmotic ultrafiltration and small-solute transport in peritoneal dialysis: a spatially distributed approach. Am. J. Physiol. Renal Physiol. 302, F1331-F1341. doi: 10.1152/ajprenal.00301.2011

Stinghen, A. E., Massy, Z. A., Vlassara, H., Striker, G. E., and Boullier, A. (2016). Uremic toxicity of advanced glycation end products in CKD. J. Am. Soc. Nephrol. 27, 354-370. doi: 10.1681/asn.2014101047

Stoenoiu, M. S., Ni, J., Verkaeren, C., Debaix, H., Jonas, J. C., Lameire, N., et al. (2003). Corticosteroids induce expression of aquaporin-1 and increase transcellular water transport in rat peritoneum. J. Am. Soc. Nephrol. 14, 555-565. doi: 10.1097/01. asn.0000053420.37216.9e

Struijk, D. G., Krediet, R. T., Koomen, G. C., Hoek, F. J., Boeschoten, E. W., vd Reijden, H. J., et al. (1991). Functional characteristics of the peritoneal membrane in longterm continuous ambulatory peritoneal dialysis. Nephron 59, 213-220. doi $10.1159 / 000186553$

Summers, L. K. (2006). Adipose tissue metabolism, diabetes and vascular diseaselessons from in vivo studies. Diab. Vasc. Dis. Res. 3, 12-21. doi: 10.3132/dvdr.2006.001

Suri, C., McClain, J., Thurston, G., McDonald, D. M., Zhou, H., Oldmixon, E. H., et al. (1998). Increased vascularization in mice overexpressing angiopoietin-1. Science 282, 468-471. doi: 10.1126/science.282.5388.468 
Szeto, C. C., Chow, K. M., Lam, C. W., Leung, C. B., Kwan, B. C., Chung, K. Y., et al. (2007). Clinical biocompatibility of a neutral peritoneal dialysis solution with minimal glucose-degradation products-a 1-year randomized control trial. Nephrol. Dial. Transplant. 22, 552-559. doi: 10.1093/ndt/gfl559

Tanabe, K., Maeshima, Y., Ichinose, K., Kitayama, H., Takazawa, Y., Hirokoshi, K., et al. (2007). Endostatin peptide, an inhibitor of angiogenesis, prevents the progression of peritoneal sclerosis in a mouse experimental model. Kidney Int. 71, 227-238. doi: 10.1038/sj.ki.5002040

Tang, S., Leung, J. C., Chan, L. Y., Tsang, A. W., Chen, C. X., Zhou, W., et al. (2004). Regulation of complement C3 and C4 synthesis in human peritoneal mesothelial cells by peritoneal dialysis fluid. Clin. Exp. Immunol. 136, 85-94. doi: 10.1111/j.1365-2249.2004.02407.x

Tjiong, H. L., Rietveld, T., Wattimena, J. L., van den Berg, J. W., Kahriman, D., van der Steen, J., et al. (2007). Peritoneal dialysis with solutions containing amino acids plus glucose promotes protein synthesis during oral feeding. Clin. J. Am. Soc. Nephrol. 2, 74-80. doi: 10.2215/cjn.01370406

Tjiong, H. L., van den Berg, J. W., Wattimena, J. L., Rietveld, T., van Dijk, L. J., van der Wiel, A. M., et al. (2005). Dialysate as food: combined amino acid and glucose dialysate improves protein anabolism in renal failure patients on automated peritoneal dialysis. J. Am. Soc. Nephrol. 16, 1486-1493. doi: 10.1681/asn.2004050402

Topley, N., Alobaidi, H. M., Davies, M., Coles, G. A., Williams, J. D., and Lloyd, D. (1988). The effect of dialysate on peritoneal phagocyte oxidative metabolism. Kidney Int. 34, 404-411. doi: 10.1038/ki.1988.195

Topley, N., Jorres, A., Luttmann, W., Petersen, M. M., Lang, M. J., Thierauch, K. H., et al. (1993). Human peritoneal mesothelial cells synthesize interleukin-6: induction by IL-1 beta and TNF alpha. Kidney Int. 43, 226-233. doi: 10.1038/ki.1993.36

Topley, N., Kaur, D., Petersen, M. M., Jorres, A., Williams, J. D., Faict, D., et al. (1996). In vitro effects of bicarbonate and bicarbonate-lactate buffered peritoneal dialysis solutions on mesothelial and neutrophil function. J. Am. Soc. Nephrol. 7, 218-224.

van Baal, J. O., Van de Vijver, K. K., Nieuwland, R., van Noorden, C. J., van Driel, W. J., Sturk, A., et al. (2017). The histophysiology and pathophysiology of the peritoneum. Tissue Cell 49, 95-105. doi: 10.1016/j.tice.2016.11.004

van de Luijtgaarden, M. W., Jager, K. J., Segelmark, M., Pascual, J., Collart, F., Hemke, A. C., et al. (2016). Trends in dialysis modality choice and related patient survival in the ERA-EDTA Registry over a 20-year period. Nephrol. Dial. Transplant. 31, 120-128. doi: 10.1093/ndt/gfv295

Velloso, M. S., Otoni, A., de Paula Sabino, A., de Castro, W. V., Pinto, S. W., Marinho, M. A., et al. (2014). Peritoneal dialysis and inflammation. Clin. Chim. Acta 430, 109-114. doi: 10.1016/j.cca.2013.12.003

Vychytil, A., Herzog, R., Probst, P., Ribitsch, W., Lhotta, K., Machold-Fabrizii, V., et al. (2018). A randomized controlled trial of alanyl-glutamine in peritoneal dialysis fluids to assess impact on biomarkers of peritoneal health and systemic inflammation. Kidney Int. 94, 1227-1237. doi: 10.1016/j.kint.2018.08.031

Waldum-Grevbo, B., Leivestad, T., Reisaeter, A. V., and Os, I. (2015). Impact of initial dialysis modality on mortality: a propensity-matched study. BMC Nephrol. 16:179. doi: 10.1186/s12882-015-0175-5

Williams, J. D., Craig, K. J., Topley, N., Von Ruhland, C., Fallon, M., Newman, G. R., et al. (2002). Morphologic changes in the peritoneal membrane of patients with renal disease. J. Am. Soc. Nephrol. 13, 470-479.

Williams, J. D., Topley, N., Craig, K. J., Mackenzie, R. K., Pischetsrieder, M., Lage, C., et al. (2004). The Euro-balance trial: the effect of a new biocompatible peritoneal dialysis fluid (balance) on the peritoneal membrane. Kidney Int. 66, 408-418. doi: 10.1111/j.1523-1755.2004.00747.x
Xiao, J., Guo, J., Liu, X. X., Zhang, X. X., Li, Z. Z., Zhao, Z. Z., et al. (2013). Soluble Tie2 fusion protein decreases peritoneal angiogenesis in uremic rats. Mol. Med. Rep. 8, 267-271. doi: 10.3892/mmr.2013.1478

Yanez-Mo, M., Lara-Pezzi, E., Selgas, R., Ramirez-Huesca, M., Dominguez-Jimenez, C., Jimenez-Heffernan, J. A., et al. (2003). Peritoneal dialysis and epithelial-tomesenchymal transition of mesothelial cells. N. Engl. J. Med. 348, 403-413. doi: 10.1056/NEJMoa020809

Yohanna, S., Alkatheeri, A. M., Brimble, S. K., McCormick, B., Iansavitchous, A., Blake, P. G., et al. (2015). Effect of neutral-pH, low-glucose degradation product peritoneal dialysis solutions on residual renal function, urine volume, and ultrafiltration: a systematic review and meta-analysis. Clin. J. Am. Soc. Nephrol. 10, 1380-1388. doi: 10.2215/CJN.05410514

Yool, A. J., Morelle, J., Cnops, Y., Verbavatz, J. M., Campbell, E. M., Beckett, E. A., et al. (2013). AqF026 is a pharmacologic agonist of the water channel aquaporin-1. J. Am. Soc. Nephrol. 24, 1045-1052. doi: 10.1681/asn.2012080869

Yoshio, Y., Miyazaki, M., Abe, K., Nishino, T., Furusu, A., Mizuta, Y., et al. (2004). TNP-470, an angiogenesis inhibitor, suppresses the progression of peritoneal fibrosis in mouse experimental model. Kidney Int. 66, 1677-1685. doi: 10.1111/j.1523-1755.2004.00935.x

Zeier, M., Schwenger, V., Deppisch, R., Haug, U., Weigel, K., Bahner, U., et al. (2003). Glucose degradation products in PD fluids: do they disappear from the peritoneal cavity and enter the systemic circulation? Kidney Int. 63, 298-305. doi: 10.1046/j.1523-1755.2003.00705.x

Zelek, W., Harris, C. L., Topley, N., Weeks, I., Lambie, M., Davies, S. J., et al. (2016). Complement biomarkers in the management of peritoneal dialysis. Immunobiology 221:1172. doi: 10.1016/j.imbio.2016.06.107

Zeng, L., Dang, T. A., and Schunkert, H. (2016). Genetics links between transforming growth factor beta pathway and coronary disease. Atherosclerosis 253, 237-246. doi: 10.1016/j.atherosclerosis.2016.08.029

Zhai, Y., Bloch, J., Homme, M., Schaefer, J., Hackert, T., Philippin, B., et al. (2012). Buffer-dependent regulation of aquaporin-1 expression and function in human peritoneal mesothelial cells. Pediatr. Nephrol. 27, 1165-1177. doi: 10.1007/ s00467-012-2120-1

Zhou, Q., Bajo, M. A., Del Peso, G., Yu, X., and Selgas, R. (2016). Preventing peritoneal membrane fibrosis in peritoneal dialysis patients. Kidney Int. 90, 515-524. doi: 10.1016/j.kint.2016.03.040

Conflict of Interest Statement: CS has obtained lecturing honoraria, travel support, and investigator-initiated research funding from Fresenius Medical care and lecturing and consulting honoraria from Baxter.

The remaining author declares that the research was conducted in the absence of any commercial or financial relationships that could be construed as a potential conflict of interest.

The handling editor declared a past collaboration with the authors.

Copyright (C) 2019 Bartosova and Schmitt. This is an open-access article distributed under the terms of the Creative Commons Attribution License (CC BY). The use, distribution or reproduction in other forums is permitted, provided the original author(s) and the copyright owner(s) are credited and that the original publication in this journal is cited, in accordance with accepted academic practice. No use, distribution or reproduction is permitted which does not comply with these terms. 